\title{
Enhancement of Student Learning in Experimental Design Using a Virtual Laboratory
}

\author{
Milo D. Koretsky, Danielle Amatore, Connelly Barnes, and Sho Kimura
}

\begin{abstract}
This paper describes the instructional design, implementation, and assessment of a virtual laboratory based on a numerical simulation of a chemical vapor deposition (CVD) process, the virtual CVD laboratory. The virtual CVD laboratory provides a capstone experience in which students synthesize engineering science and statistics principles and have the opportunity to apply experimental design in the context similar to that of a practicing engineer in industry with a wider design space than is typically seen in the undergraduate laboratory. The simulation of the reactor is based on fundamental principles of mass transfer and chemical reaction, obscured by added "noise." The software application contains a 3-D student client that simulates a cleanroom environment, an instructor Web interface with integrated assessment tools, and a database server. As opposed to being constructed as a direct one-to-one replacement, this virtual laboratory is intended to complement the physical laboratories in the curriculum so that certain specific elements of student learning can be enhanced. Implementation in four classes is described. Assessment demonstrates students are using an iterative experimental design process reflective of practicing engineers and correlates success in this project to higher order thinking skills. Student surveys indicate that students perceived the virtual CVD laboratory as the most effective learning medium used, even above physical laboratories.
\end{abstract}

Index Terms-3-D computer simulation, chemical vapor deposition (CVD), experimental design, instructional scaffolding, thinkaloud, virtual laboratory.

\section{INTRODUCTION}

$\mathbf{T}$ HE traditional undergraduate laboratory class is delivered in a mode where small student teams work with dedicated equipment physically located in a laboratory. Students are typically tasked with taking a set of experimental measurements, analyzing the data, often in the context underlying theory in the curriculum, and reporting the findings. The pedagogical value of the hands-on experience that a laboratory provides is ubiquitously endorsed by educators [1]. However, in practice the engineering laboratory has limitations as well. The traditional mode of delivery requires large amounts of resources for a high quality student experience since students must be supervised and equipment is expensive to purchase and maintain. Moreover, versatile

Manuscript received August 21, 2006; revised August 1,2007. This work was supported by the Intel Faculty Fellowship Program and the National Science Foundation's Course, Curriculum and Laboratory Improvement Program, Educational Materials Development, under Grant DUE-0442832. Any opinions, findings, and conclusions or recommendations expressed in this material are those of the author(s) and do not necessarily reflect the views of the National Science Foundation.

The authors are with the Department of Chemical Engineering, Oregon State University, Corvallis, OR 97331-2702 USA (e-mail: koretsm@engr.orst.edu).

Digital Object Identifier 10.1109/TE.2007.906894 laboratory experiences are needed that can accommodate students enrolled via distance education.

A possible way to overcome the limitations of the traditional physical laboratory is to use alternative modes of delivery. One alternative approach is the use of Web-based remote delivery and virtual laboratories. In the remote delivery mode, students off site can control the equipment and collect data using a Web-based interface. Examples have been reported in process control, power electronics, networking, fluid mechanics, photonics, and digital signal processing [2]-[8]. In a virtual laboratory, simulations based on mathematical models implemented on a computer can replace the physical laboratory. In the most straightforward manner, the virtual laboratory is used as an alternative mechanism for achieving the same learning outcomes as in the corresponding physical laboratory. Virtual versions of standard laboratories have been developed and integrated into engineering [9]-[11] and science [12]-[14] curricula.

The effectiveness of Web-based remote laboratories and virtual laboratories as a direct replacement of their physical counterparts has been assessed. Several researchers have concluded that student learning is not detrimentally affected by using Webbased remote laboratories; in fact, students appreciate the flexibility that they offer [2], [4]-[8]. Analogous studies indicate that no significant difference in student learning results from using virtual laboratories versus physical laboratories [15], although feedback from students indicates that the complete removal of physical laboratories from the curriculum would not be welcome [10]. One study examined a laboratory delivered to mechanical engineering juniors in all three modes [16]. The authors describe differences in the achievement of student learning outcomes based on mode of delivery. While a given mode improves some learning outcomes, others diminish. For example, the authors report that students who experienced the nonproximal (Web-based or virtual) modes showed deeper levels of cognition in aspects of analysis of the data, both being more likely to identify nonidealities in the experimental results and more likely to demonstrate an understanding of the consequences of the nonidealities. However, as compared to the Web-based remote mode, students experiencing the virtual mode displayed a lesser grasp of the real context, even with both groups using identical interfaces. The authors suggest that if instructors choose an alternative mode as a deliberate educational choice, rather than a convenient alternative, they can improve certain specific learning outcomes in laboratories.

Indeed, a few cases have employed an alternative paradigm where the virtual laboratory was constructed as a complement to the physical laboratory. When viewed in this way, a virtual 
laboratory can be designed to extend the range of the learner specifically, allowing completion of tasks not otherwise obtainable. A virtual laboratory in circuits was used as a "primer" to complement the corresponding physical laboratories [17]; the intent was to orient the student for the physical laboratory to come. The authors suggest that this approach can elicit learning outcomes that are not possible from completion of a standalone physical laboratory, such as allowing students to go through a debugging process for which they typically do not have time. A virtual laboratory has been developed to allow students to apply the Taguchi method to determine the 14 design parameters of an extrusion process in just 90 minutes [18]. The simulation, which was based on an arbitrary mathematical model, performs the experiments and calculates the relevant statistics, freeing students to do other tasks. In particular, students compare their results from a trial and error approach to results from the more structured Taguchi method. In contrasting scope, a capstone environmental engineering design project used a virtual laboratory to allow students to perform as a field engineer, drilling boreholes, collecting core samples, constructing wells, collecting groundwater samples, submitting samples for laboratory analysis, and executing hydraulic and transport experiments at a virtual hazardous waste site [19]. The assessment indicates that students gained deep content knowledge, linking theory to real-world applications; additionally, students reported an improvement in their ability to handle complex projects and problem-solving skills [20].

This paper describes the virtual chemical vapor deposition (CVD) laboratory, which has been designed to promote student learning in ways that are difficult to address with the physical laboratories at the university. First, because of its structure, the virtual CVD laboratory allows students to experience the complete, iterative experimental design process typical of practicing engineers. Second, the context of the project is reflective of the physical and social context found in industry, and the solution process encourages students to synthesize and toggle between statistics and engineering science concepts. These aspects facilitate integration and transfer of knowledge. The instructional design, software design, implementation, and assessment of the virtual CVD laboratory are presented.

\section{InSTRUCTIONAL DESIGN AND PEDAGOGY}

An overview of the virtual CVD laboratory with a focus on how it applies relevant educational theory to promote student learning of experimental design is presented in this section.

\section{A. The Virtual Chemical Vapor Deposition Reactor}

CVD is an important unit process used to grow thin films in the manufacture of integrated circuits and other devices [21]. While laboratories in semiconductor processing have been implemented in the university environment [22]-[24], they tend to be resource intensive and utilize equipment many generations older than found in industry. The virtual CVD laboratory is based on a state-of-the-art industrial scaled vertical reactor, schematically shown in Fig. 1. The particular reaction used is the deposition of silicon nitride $\left(\mathrm{Si}_{3} \mathrm{~N}_{4}\right)$ from ammonia $\left(\mathrm{NH}_{3}\right)$ and dichlorosilane $\left(\mathrm{SiCl}_{2} \mathrm{H}_{2}\right.$ or DCS) gases. The virtual laboratory is based on a simulation using fundamental principles of

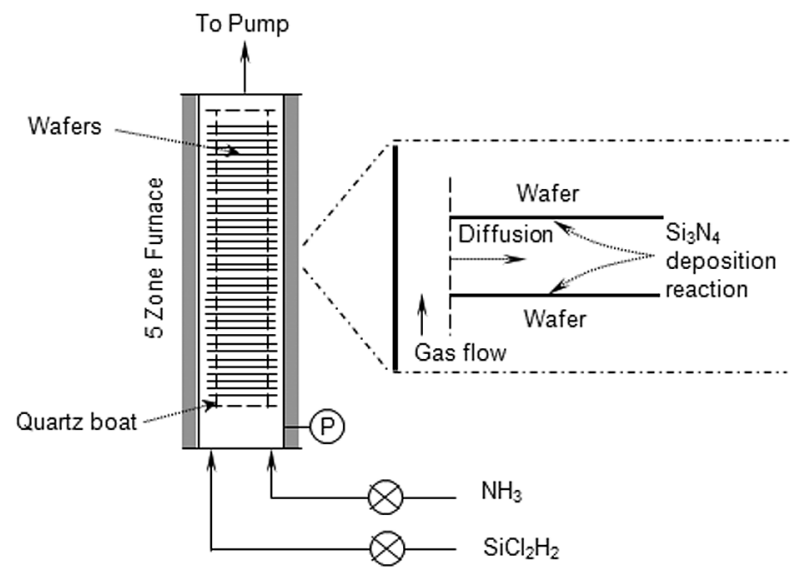

Fig. 1. Schematic diagram of a CVD reactor.

mass transfer and chemical reaction, obscured by added "noise." More detail of the mathematical model is provided elsewhere [25]. Rather than having access to the entire output of the model, the film thicknesses are provided to students only at the points that they have decided to "measure." Since the reactor outputs are reflective of the chemical and physical phenomena occurring within the system, those students who integrate their fundamental engineering science knowledge should be more efficient with the experimental design. This approach is intended to allow conceptual integration of statistics and engineering science and lead to deeper understanding of both topics.

Students use the virtual reactor in the same manner as they would use a reactor in industry. They are tasked with optimizing reactor performance based on experimentation. In completing this project, they need to choose the values for the nine parameters for each of the runs they perform and choose the wafers and wafer locations on which film thickness measurements are made. Since student runs and measurements have a cost associated with them, a realistic economic constraint is present. This aspect discourages the use of unstructured trial and error approaches. The most effective performance will be a balance between optimization of performance and cost. Not only must students learn how to apply experimental design, they must also determine when their results are good enough, so that they can submit their "recipe" for production.

\section{B. Experimental Design in Engineering Education}

Experimental design is an essential but difficult skill to integrate into the engineering curriculum. The complete experimental design process used by those people who can be considered experts, for example, experienced practicing engineers or research scientists, is generically depicted in the flowchart shown in Fig. 2. The expert conducts experiments to obtain information about a problem that has been identified. The next step in the process is to design the experiment. This step includes selection of the dependent variables (responses) and the independent variables (factors) to be investigated. An appropriate sequence of experiments, often in the form of a design of experiments (DOE) array, is then created. The experiments are then performed where the independent variables are set to specified values and the dependent variables are measured. The data are 


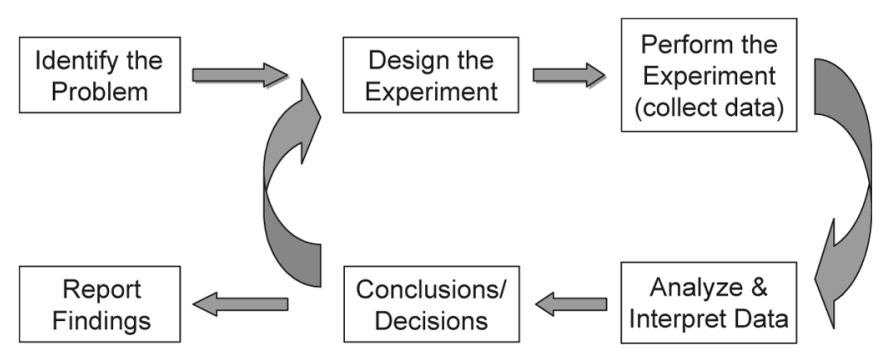

Fig. 2. Flowchart of expert approach to experimental design.

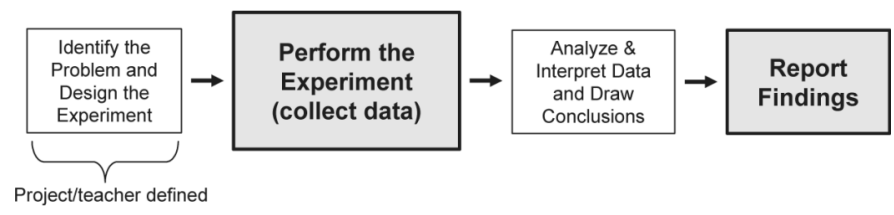

Fig. 3. Schema of the exposure of an undergraduate student to experimental design in the physical laboratory. The shaded boxes represent activities that consume the majority of the students' cognitive capital.

then summarized and analyzed using the appropriate statistical methods. The physical meaning of these data is inferred. Based on the analysis, the practical significance of the findings is determined; conclusions are drawn; and decisions are made. The decision often consists of identifying the next set of experiments that need to be conducted to answer the question. In this case, the design/analysis process is repeated, as represented by the curved arrow in Fig. 2. Being adaptable and creative as they iterate is a trademark of successful experts. Finally, when the iterative process is complete, the findings are communicated in written or oral form.

A desired learning outcome in providing undergraduate laboratory classes is to get students to learn the experimental design methodology as practiced by experts and shown in Fig. 2. However, the experience students have in the undergraduate laboratory can be dramatically different. A schema representing a common experimental process flow applied to physical engineering laboratory experiments is depicted in Fig. 3. Because of the structure of the physical laboratory, certain portions of the experimental process are emphasized over others. For purposes of this work, cognitive capital is defined as the finite amount of mental energy and time that a student has to invest in the completion of a laboratory or project. Those steps that occupy the majority of the student's cognitive capital are shaded in Fig. 3. To the students performing the actual experiment, getting the physical equipment to operate properly and obtaining the data are viewed as the paramount goals of the laboratory experience.

Students tend to view the laboratory as complete when they successfully use the laboratory equipment to obtain a meaningful set of data. This step often consumes a majority of the student's cognitive capital. The other major activity is the laboratory report upon which they are assessed and receive their grade. When their cognitive capital is spent on these activities, little remains for the critical steps of experimental design and analysis of data. In fact, the experimental design is often determined by the instructor and provided for the student. Furthermore, resource and time limitations diminish the likelihood that

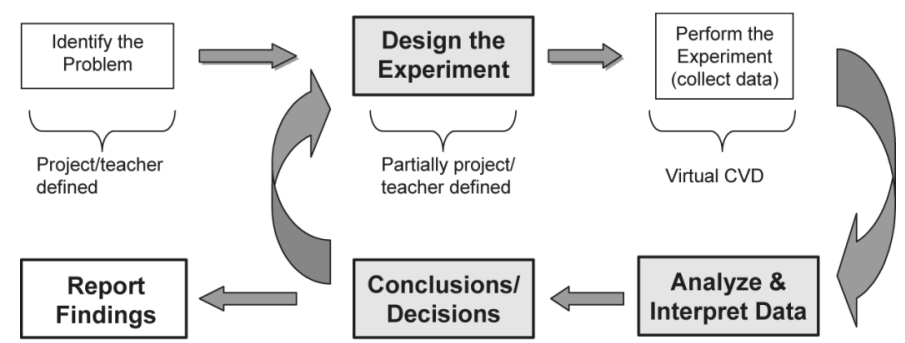

Fig. 4. Schema of the exposure of a student to experimental design in the virtual CVD laboratory.

students can use their results to identify and perform further experiments. Thus, the process depicted in Fig. 3 is linear, as opposed to the iterative process shown in Fig. 2.

\section{Problem-Based Learning Through Instructional Scaffolding}

The instructional design of the virtual CVD laboratory applies problem-based learning (PBL) to promote student learning of experimental design. PBL focuses on student-centered learning where instructional scaffolding is used to enable students to complete an authentic, open-ended problem successfully. Educational research into the effectiveness of PBL suggests four principles of good design for PBL: setting learning appropriate goals, providing scaffolding that promotes both student and teacher learning, providing formative assessment opportunities, and using social interactions to promote participation [26], [27].

Instructional scaffolding is an instructional tool that provides support, extends the range of the learner, and permits the completion of tasks not otherwise possible. The scaffolding is designed to be gradually removed as the students become more competent [28]. Scaffolding can be likened to training wheels in that scaffolding enables students to engage in more advanced activities that require a deeper level of cognition than would be possible without the presence of the scaffolding [29]. The virtual CVD laboratory acts as scaffolding by simulating the physical operation of the process and metrology equipment. This scaffolding allows a student to experience a different emphasis on the experimental design process than they typically encounter in a physical laboratory. A schema of the experimental process flow utilized in this virtual laboratory is depicted in Fig. 4. The student is provided with a problem statement which includes a set of independent variables to explore and a mechanism to measure the response variable. Student effort is then focused on developing an experimental strategy (often in the form of a DOE design array) to explore the design space and solve the problem. In contrast to a physical laboratory experience, the next step in the process is performed virtually by the simulation. Therefore, this step consumes a relatively small amount of the student's cognitive capital and is not shaded in Fig. 4. Thus, the student can invest cognitive capital on the analysis and interpretation of the data, and also on applying their conclusions to iterate on the experimental design. This process continues until the student decides that the problem is solved, at which time he or she reports the findings. In these ways, the experimental approach offered by the virtual CVD laboratory is reflective of the approach of practicing engineers depicted in Fig. 2. 
Furthermore, the cognitive processes needed to complete these tasks complement the haptic skills emphasized in typical physical laboratories. Specifically, students will need to operate at the highest cognitive levels of Bloom's taxonomy [30]—analysis, synthesis and evaluation- to navigate the experimental design process successfully.

The virtual CVD laboratory also applies the idea of situated cognition by replicating key aspects of the social and physical environment prevalent in industry. Situated cognition contends that situations coproduce knowledge with activity. Therefore, the method and content should be properly situated and reflect the desired outcomes of the learner [31]. Applying situated cognition to the engineering classroom suggests that by utilizing learning tools that replicate the social and physical context typically found in the workplace, engineering students will be able to more effectively transfer their cognitions and apply them to realistic engineering project work. One such aspect is both the goal and approach to experimentation. A practicing engineer does not routinely conduct experiments to elucidate fundamental principles, as is often the intended outcome in the undergraduate laboratory. More likely, the practicing engineer seeks to optimize performance of a process by investigating the effect of the input variables. Similarly, optimization of film uniformity is the direct student deliverable in the virtual CVD laboratory project. Students must account for cost constraints since they are charged virtual money for each run and measurement. Furthermore, the physical equipment modeled in this virtual laboratory is reflective of equipment and throughput currently found in cutting-edge semiconductor factories in that two hundred $300 \mathrm{~mm}$ wafers are processed in a batch. In contrast, a teaching laboratory at the university typically uses one to five $50 \mathrm{~mm}$ wafers. Therefore, specific cognitive tasks that a practicing engineer performs in a high-volume manufacturing plant, such as maximizing axial uniformity in the reactor, are not elicited by typical university laboratories. Even the physical look of a cleanroom is replicated in the 3-D student client, which allows a student to become familiar with this unique manufacturing environment.

Clearly, many benefits of integrating team work into engineering education exist. However, the sociocognitive interactions among members of a team of practicing engineers can be distinctively different among students in a physical laboratory at the university. The term sociocognitive interaction refers to both how the social dynamic of the group affects the cognitive activities of the individual, and how the cognitive tasks affect the social dynamic. The effective team of engineers collaborates to resolve high level cognitive tasks, such as experimental design, data interpretation, and the iterative process of redesign shown in Fig. 2. When student teams operate a physical laboratory in the mode depicted in Fig. 3, the haptic skills in collecting data and the verbal skills of communicating results are where collaboration inevitably occurs. The nature of the respective cognitive tasks drives different types of interaction between team members. Moreover, this social interaction is an important factor in determining the direction of the project. Inspection of Fig. 4 shows that the virtual CVD laboratory emphasizes the high level cognitive tasks of design and analysis, and consequently, promotes the type of sociocognitive interactions found in teams of practicing engineers.

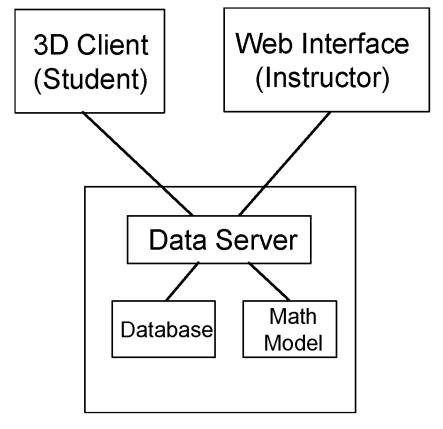

Fig. 5. Main software components of virtual CVD laboratory.

\section{Software Design AND FEATURES}

The virtual CVD laboratory software is designed to ensure ease of transportability and adoptability to different educational programs. Instructors who want to use the software in a course can sign up for an instructor account via the virtual CVD laboratory Web page [32]. The software is designed as three independent components: the 3-D student client, the instructor Web-based interface, and the data server. The relationship between these components is shown in Fig. 5. More details of the software can be found elsewhere [25].

The 3-D student client is a three-dimensional graphical interface that provides the look-and-feel of a typical semiconductor manufacturing environment. From here, the students can make reactor runs, take measurements, and obtain output data. Fig. 6 displays screen-shots of this interface. The reactor bay is shown in Fig. 6(a). The reactor input screen [Fig. 6(b)] allows the student to specify the nine operating parameters needed to grow the $\mathrm{Si}_{3} \mathrm{~N}_{4}$ thin films (five temperature zones, flow rates of ammonia and dichlorosilane feed gases, the reactor pressure and the reaction time). After the student has run a batch of wafers through the virtual reactor, that student can navigate to the metrology bay where access is available to a virtual ellipsometer to measure the film thicknesses. Fig. 6(c) displays a view of the ellipsometer console used to choose measurement sites for a specific wafer. From these data, students can estimate the overall film uniformity. After the students have their final optimized reactor settings, they can submit the process recipe to production via the 3-D student client.

The second component, the instructor Web interface, allows the instructor to set up student accounts, view the students' interactions with the virtual CVD laboratory, and customize reactor parameters, if so desired. The difficulty of real-time assessment has been identified as a limitation to the effectiveness of physical laboratories [33]. To address this issue, the virtual CVD laboratory is designed with integrated assessment tools. The instructor Web interface contains an overview page, which shows the total number of furnace runs, measurement sets, and total cost. By clicking on a student's account name, the instructor can view the student's chosen reactor parameters for each run, and the student's measurement points and resulting measured values for each measurement set. The time at which the run or measurement set was made is also shown. An example of a set of student data is shown in Fig. 7(a). These data can also be exported 


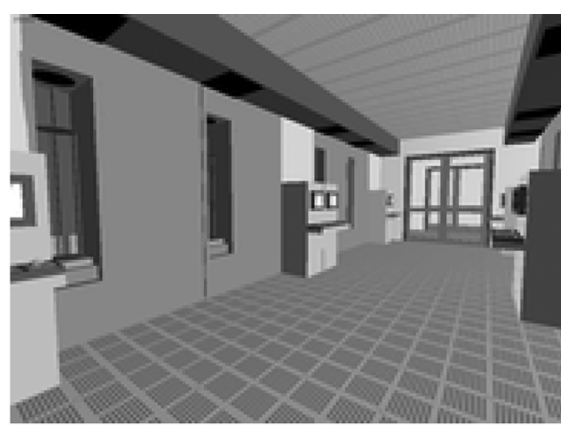

(a)

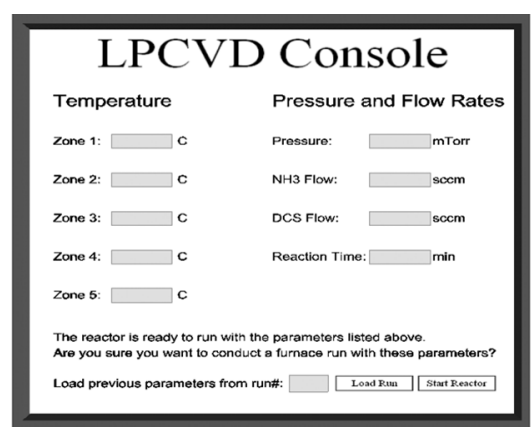

(b)

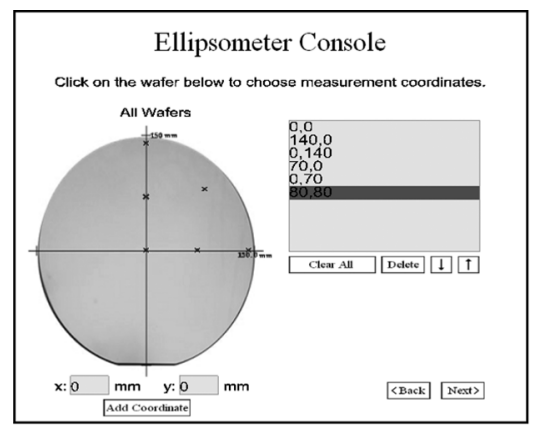

(c)

Fig. 6. Screen shots of the virtual CVD 3-D student client. (a) CVD reactor bay in the virtual factory. (b) Virtual CVD reactor parameter inputs. These parameters must be input by the student to run the reactor. (c) Selection of measurement points on a wafer.

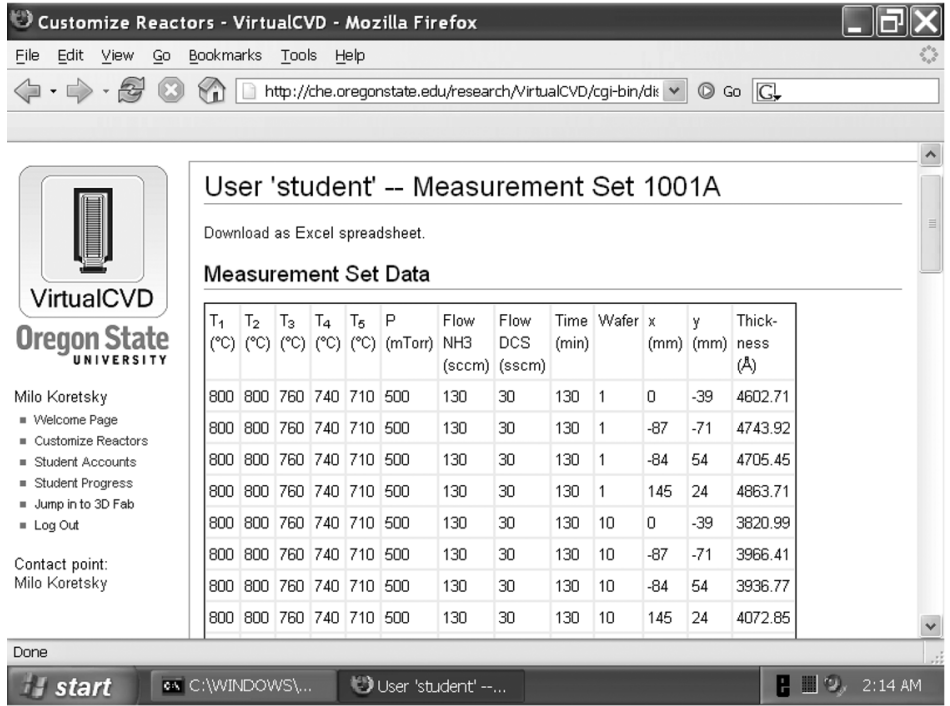

(a)

\section{Reactor 1}

\begin{tabular}{ll|} 
Number of temperature zones: & $5 \quad \mathrm{~m}$ \\
Maximum number of wafers: & 200 \\
Wafer radius: & 150 \\
Wafer spacing: & 10.0 \\
Target film thickness: & 1500.0 \\
Cost per run: & 5000.0 \\
Cost per measurement: & 75.0 \\
Measurement error $\sigma:$ & 4.0 \\
\end{tabular}

Thermocouple:

Wafer position:

Temperature bias $\left({ }^{\circ} \mathrm{C}\right)$

\begin{tabular}{|c|c|c|c|c|}
\hline 1 & 2 & 3 & 4 & 5 \\
\hline 1 & 50 & 100 & 150 & 200 \\
\hline 0.0 & 0.0 & 0.0 & 0.0 & 0.0 \\
\hline
\end{tabular}

\section{Submit Changes}

(b)

Fig. 7. Instructor Web interface. (a) View of a student's furnace runs and measurement data. (b) Reactor parameters which may be customized by the instructor.

to a Microsoft Excel spreadsheet, as individual runs, measurement sets, or as a single combined spreadsheet. This feature enables formative assessment by allowing the instructor to provide real-time feedback to the students.

Summative assessment, or assessment of individual achievement, is automatically generated by the learning tool upon student completion of the assignment. First, a summary of the performance for each submitted final recipe is available in tabular form. This table reports the overall uniformity, standard error off target, the gas utilization, and the total cost for each student group with the chosen reactor parameters. Second, the standard error off target is plotted in graphical form for different axial positions along the reactor. Interpreting this graph and relating the graph to the table summarizing students' results, an instructor can assess how well a given group optimized the reactor. Assessment results from the instructor Web interface are presented elsewhere [25].

Additionally, the instructor can customize the reactor behavior using the instructor Web interface. Instructors who do not wish this level of specificity can simply use the default values. Default reactor settings are shown in Fig. 7(b). From this interface, the instructor may change the number of wafers, wafer radius, wafer spacing, and the virtual "cost" that the student is charged for making each furnace run and measurement set. The instructor can also change the number of temperature zones, the position of the thermocouple within each zone, and the "bias" associated with it. This feature allows unique solutions from year to year. Experimental errors are added to the students' measured film thicknesses via a normal distribution with standard deviation, $\sigma$. The instructor can change the parameter $\sigma$, so that smaller or larger experimental errors are observed by students.

The data server performs all of the calculations, stores data, carries out actions requested by users, and sends results back to users. The data server has several subcomponents: a mathematical model which is used to determine the film thicknesses on the wafers, a database used to store user relationships and data measured within each user account, and an XML-RPC server which runs as a daemon and handles requests from the 3-D student client and the instructor Web interface.

\section{IMPLEMENTATION}

A summary of the experimental activity in the classes that have used the virtual CVD laboratory is shown in Table I. In 
TABLE I

SUMMARY OF EXPERIMENTAL ACTIVITY OF THE VIRTUAL CVD LABORATORY

\begin{tabular}{|c|c|c|c|c|c|c|}
\hline Class & Term & Students & Groups & Runs & Measurements & Virtual Cost \\
\hline ChE 444 & W 05 & 24 & 8 & 97 & 2,672 & $\$ 685,400$ \\
\hline ChE 444 & W 06 & 28 & 8 & 122 & 2,241 & $\$ 778,075$ \\
\hline $\mathrm{UO}$ & Su 06 & 11 & 3 & 40 & 538 & $\$ 240,350$ \\
\hline SESEY & Su 06 & 4 & 4 & 146 & 6,413 & $\$ 1,210,975$ \\
\hline $\begin{array}{l}\text { ChE } 414 \\
\text { Project } 1 \\
\text { Project } 2\end{array}$ & F 06 & 52 & 23 & $\begin{array}{l}384 \\
572\end{array}$ & $\begin{array}{l}5,293 \\
33,136\end{array}$ & $\begin{array}{l}\$ 2,316,975 \\
\$ 5,345,200\end{array}$ \\
\hline Total & & 119 & 46 & 1,361 & 50,293 & $\$ 10,576,975$ \\
\hline
\end{tabular}

winter 2005 (W 05) and winter 2006 (W 06), the virtual laboratory was used in a senior-level undergraduate and graduate elective chemical engineering course at Oregon State University (OSU), Corvallis, Thin Film Materials Processing (ChE 444/ 544), where CVD is a core topic. Beginning fall 2006 (F 06), the virtual CVD laboratory was integrated into the first course of the required chemical, biological, and environmental engineering capstone laboratory sequence ( $\mathrm{ChE} 414)$. In this course, two lectures were delivered to provide students the necessary background knowledge of the CVD process. In addition to the classes at OSU, the virtual CVD laboratory was implemented remotely in the Semiconductor Processing and Device Characterization MS Program at the University of Oregon (UO), Eugene. In summer 2006 (Su 2006), 11 graduate students completed the virtual CVD laboratory. This case illustrates a strength of the virtual CVD laboratory as an educational tool; the virtual laboratory can be creatively adapted to fit in and support any number of different curricular structures at remote locations. The virtual CVD laboratory was also used in a summer outreach program called Summer Experience in Science and Engineering for Youth (SESEY).

In the capstone laboratory sequence, the virtual laboratory was the first laboratory the students completed. The intent was to have every $\mathrm{ChE}$, BioE, and EnvE undergraduate gain critical experience in the entire cycle of applying experimental design methodology prior to their experience with real equipment in the laboratory. The student teams next engaged in three relatively structured physical unit operation experiments. These laboratories focused on developing haptic skills. Finally the laboratory sequence culminated in an open-ended project, where the focus is on working independently, developing a project proposal, designing the experiment, completing experimental work, analyzing the data, and writing a final technical report that included recommendations for future work. In terms of instructional scaffolding, the final project reflects the case of removed scaffolding.

Before being granted access to the reactor, each group needed to develop a "preliminary design strategy" which had to be reviewed by the group and the instructor. To determine their initial reactor parameters, the students had to apply concepts learned in core engineering classes to this open-ended problem. This task was a direct indication of their cognitive ability to synthesize. In addition, the students needed to review the literature to determine realistic operating conditions; this task gave insight into their critical evaluation skills. The "preliminary design strategy" process ensured that the groups had a well planned approach before making runs, and was used so that students did not approach this project as a video game. As an application of situated cognition, this design strategy process is in analogy to obtaining management approval in industry.

In total, over 1,300 reactor runs have been made, and over 50000 measurements have been taken. This high level of activity is unusual in a physical laboratory, even for much simpler experiments, and indicates that the virtual CVD laboratory is achieving its intended design of instructional scaffolding.

\section{ASSESSMENT}

A behavioral objective evaluation approach was implemented to measure the degree to which the intended learning outcomes of the virtual CVD laboratory had been met. Specifically, the assessment addressed the alignment between the students' experimental approach and the experts' approach (depicted in Fig. 2) and quantified the higher cognitive activity demonstrated by the students. Students' perception of the effectiveness of the virtual laboratory and their learning achievement was also measured.

\section{A. Assessment of the Experimental Approach Used by Students}

Traditional assessment methods, such as quizzes and tests, are effective for measuring the acquisition of facts, concepts and discrete skills. However, these methods have been shown to be less effective in assessing higher order cognitive activity than performance tasks that are designed to simulate real-world scenarios [34]. Because of the situated nature of the virtual CVD laboratory, completion of the project itself consists of such a set of performance tasks. Therefore, a task analysis of the students' approach to the project is an essential aspect of the virtual CVD assessment.

Six student groups participated in a "think-aloud" study to collect assessment data. In the "think-aloud" technique, students are observed while they verbalize their thought processes. This technique has been shown to give insight to their cognitive processes, especially in situations where higher order critical thinking ability is needed [35]. The "think-aloud" sessions entailed observation of the student groups throughout the entire virtual CVD project. All sessions were captured with an audio-recording device and later analyzed and coded to provide insight into the experimental design approach. Additionally, significant sociocognitive interactions and their effect on making key decisions were recorded. A task analysis was performed on the qualitative data to represent the unique experimental path 


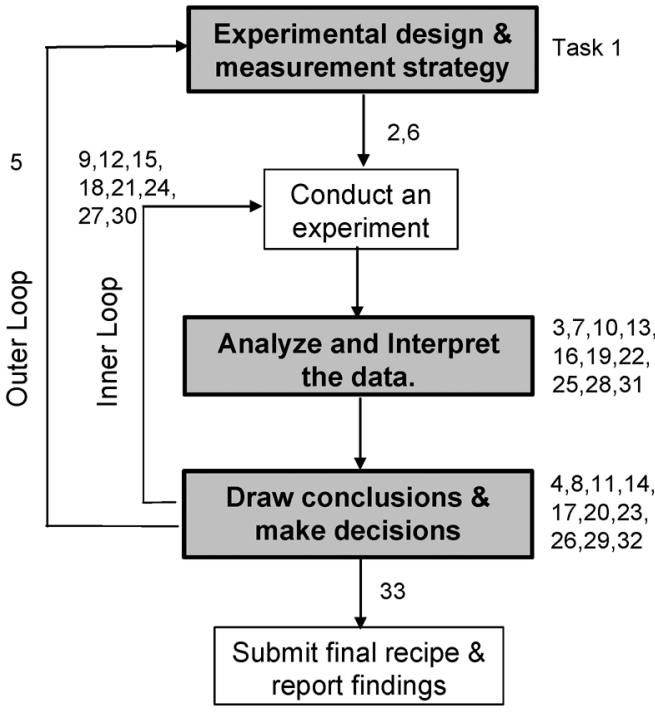

(a)

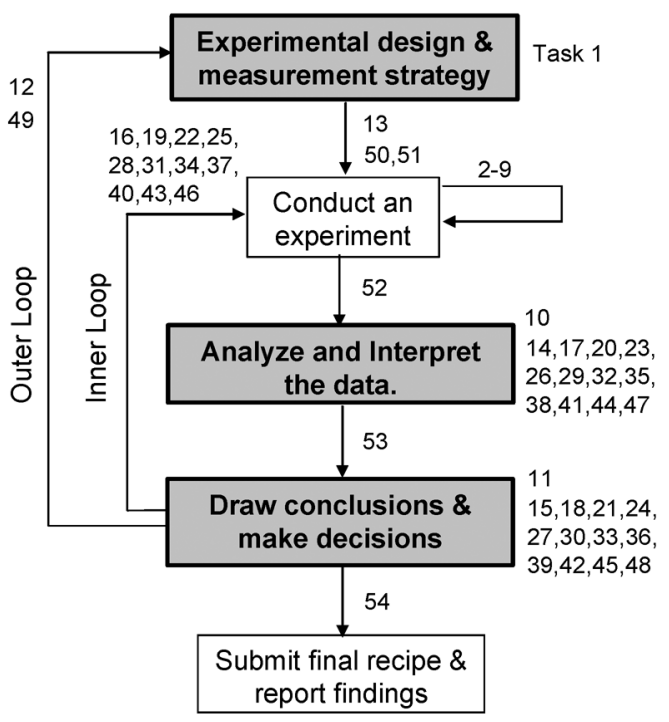

(b)

Fig. 8. Experimental paths derived from analysis of think-aloud sessions from two representative student groups. (a) Group A. (b) Group B.

taken by the student group. From this analysis, alignment with the desired experimental approach can be measured.

Schemas representing the experimental path taken by two student groups are depicted in Fig. 8. The sequence of tasks completed by the groups is indicated numerically in the schemas. For example, Group A, represented in Fig. 8(a), started the project with an experimental design based on a 2 level, 3 factor, full factorial DOE design array (task 1). After completing the first run in the array (task 2), they analyzed the data (task 3 ) and concluded that they were too far away from the target thickness (task 4). Their experimental approach degenerated to onefactor-at-a-time (task 5), and they proceeded to perform a series of single experiments, each followed by an analysis step (tasks 6-32). They continued this cycle of experimentation and analysis until they concluded that they had successfully optimized the process (task 32), at which time they submitted their final process recipe (task 33 ).

The experimental path of Group B, shown in Fig. 8(b), reveals two distinct differences from Group A. First, Group B completed all eight of the runs prescribed in their DOE (tasks 2-9). Second, this group expanded the scope of the project to investigate some additional issues to evaluate if better uniformity could be achieved (task 49). Specifically, the group performed identical measurements on different ellipsometers and performed a replication run on the reactor using the final conditions (tasks 50-51); these experiments allowed them to determine the repeatability and reproducibility of the equipment, and let them know the statistical uncertainty of the process and the measurements (task 52).

Group A abandoned their planned DOE for one-factor at a time experimentation, and, therefore, needed to expend cognitive capital in the analysis which followed each run. In contrast, Group B completed their DOE, and, in addition, performed a measurement system analysis and a confirmation run. Group B was able to complete these additional tasks since they still had cognitive capital in reserve. This type of initiative is reflective of high performing engineers in industry and confirms the situated nature of the cognitive activity. Moreover, the fact that Group B completed these extra tasks is reflective of their perception of the virtual laboratory. If they did not consider this laboratory as "real", they would not pursue this type of statistical verification. Hence, this virtual laboratory appears to be capable of engaging students in just as "real" a manner as a physical laboratory.

Inspection of the schemas in Fig. 8 shows both Groups A and B achieved several iterative cycles. Group A completed one design cycle (outer loop) and eight analysis cycles (inner loop), while Group B completed two outer loops and 11 inner loops. Similarly, results from the task analysis from the other groups participating in the think-aloud sessions have been compiled and are shown in Table II. In all six cases, the groups demonstrated an iterative approach to experimental design, completing an average of 3.3 design loops and 11.5 analysis loops. This evidence suggests that students were engaged in the intended experimental approach that is depicted in Fig. 4.

This analysis of the "think-aloud" sessions validates that the virtual CVD laboratory provides instructional scaffolding. The virtual laboratory minimizes the cognitive capital required to perform an experiment mechanically and, therefore, gives students a much broader experience in experimental design. Additional analysis of the think-aloud sessions was performed to give insight into sociocognitive interactions and their effect on key decision points. Primary decision nodes were influenced just as often by the personality dynamics of the team members as by technical veracity of the different approaches, if not more so. This result suggests that the social nature of group interaction plays a significant role in the experimental path, the overall achievement, and the degree of learning. Further investigation of the effect of sociocognitive interactions is warranted.

\section{B. Assessment of Higher-Order Cognitive Activity}

Evidence of cognitive activity requires a cognitive model that specifically reflects what students are intended to learn [36]. 
TABLE II

TASK ANALYSIS SHOWING EXPERIMENTAL APPROACH

\begin{tabular}{|c|c|c|c|}
\hline Group & \# Outer (Design) Loops & \# Inner (Analysis) Loops & \# Tasks \\
\hline A & 1 & 8 & 33 \\
\hline B & 2 & 11 & 54 \\
\hline C & 3 & 22 & 79 \\
\hline D & 6 & 4 & 33 \\
\hline E & 5 & 13 & 64 \\
\hline F & 3 & 11 & 56 \\
\hline Average & $\mathbf{3 . 3}$ & $\mathbf{1 1 . 5}$ & $\mathbf{5 3 . 2}$ \\
\hline
\end{tabular}

TABLE III

ASSESSMENT Data Student CouRSE EVALUATIONS Using a LiKERT-SCALE

\begin{tabular}{|c|c|c|c|}
\hline \multirow{2}{*}{$\begin{array}{l}\text { Assessing the degree to which the course learning } \\
\text { outcomes were met: }\end{array}$} & \multicolumn{3}{|c|}{ Score } \\
\cline { 2 - 4 } & $\mathbf{2 0 0 5}$ & $\mathbf{2 0 0 6}$ & Average \\
\hline $\begin{array}{l}\text { I am able to systematically optimize the performance of } \\
\text { a CVD reactor for as low a cost as possible. }\end{array}$ & $71 \%$ & $73 \%$ & $72 \%$ \\
\hline Combined score for all other objectives & $80 \%$ & $71 \%$ & $75.5 \%$ \\
\hline Measuring the effectiveness of learning media: & & \\
\hline The effectiveness of the Virtual CVD laboratory was ... & $84 \%$ & $78 \%$ & $81 \%$ \\
\hline The effectiveness of the physical laboratories was ... & $74 \%$ & $77 \%$ & $75.5 \%$ \\
\hline The effectiveness of the industrial seminars was ... & $76 \%$ & $75 \%$ & $75.5 \%$ \\
\hline The effectiveness of the homework was ... & $65 \%$ & $70 \%$ & $67.5 \%$ \\
\hline The effectiveness of the literature reviews was ... & $68 \%$ & $62 \%$ & $65 \%$ \\
\hline
\end{tabular}

The development of an appropriate cognitive model becomes increasingly more difficult as increasingly higher level thinking is required. One of the first taxonomies of learning, developed by Bloom in 1956, describes six successively deeper levels of cognition that culminate with the highest level of cognitions-analysis, synthesis, and evaluation [30]. More recently, Shavelson developed a taxonomy of learning that distinguishes between declarative, procedural, and schematic knowledge [37]. The experimental approach that the virtual CVD laboratory intends to elicit has inherent alignment with Bloom's higher level cognitions. The steps in the expert's experimental design process (Fig. 2) "Design the Experiment," "Analyze \& Interpret Data," and "Conclusions/Decisions" correspond directly to the synthesis, analysis, and evaluation levels of Bloom's taxonomy.

The written reports of eight student groups were analyzed for evidence of higher-order cognitive activity. For each group, a count of the number of statements present in the written reports which demonstrate analysis, synthesis, and evaluation was performed. Fig. 9 shows a plot of the number of statements versus the group's written report score and the instructor assessment of the achievement of learning outcomes, as demonstrated both in the written and oral reports. Both scores track proportionately with the number of high cognition statements, with the former showing saturation because scores could not exceed 100. One can infer that more activity in the higher cognitive domain results in better project performance.

\section{Assessment Through Course Evaluations}

Assessment data were collected from Likert-scale statements that were part of the overall $\mathrm{ChE} 444 / 544$ course evaluations in

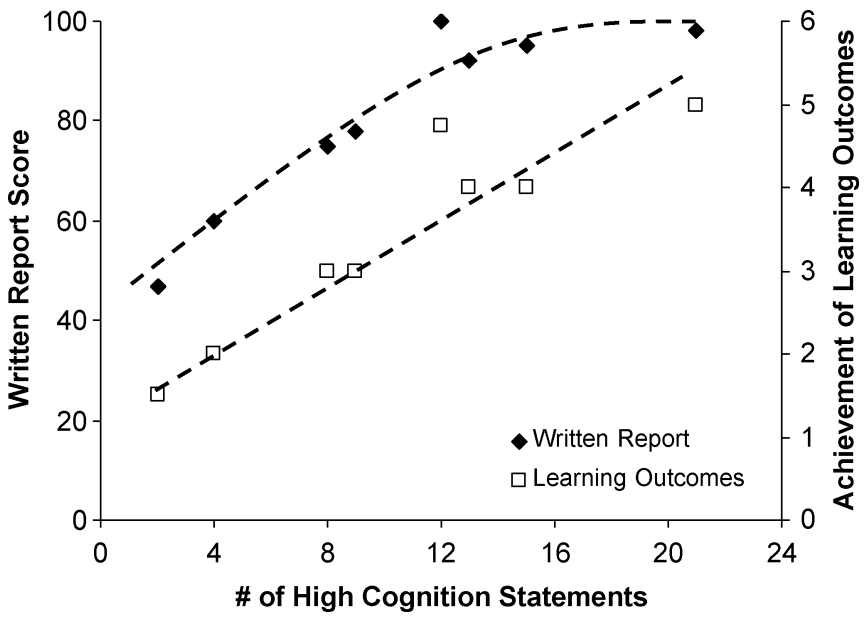

Fig. 9. Evidence of higher cognitive activity and the impact of such activity on written report score and achievement of learning outcomes.

winter 2005 and in winter 2006. The evaluation statements were designed to assess how well the student felt the course learning outcomes were satisfied and to measure the effectiveness of the different learning media used in the course. One of the six course learning outcomes was specific to the outcome resulting from completing the virtual CVD laboratory. In addition, the effectiveness of the five learning media that were utilized in this course (physical laboratories, seminar speakers from industry, traditional homework assignments, a literature review, and the virtual CVD laboratory) were rated by the students. These evaluation statements and results are shown in Table III. 
Analyzing these assessment results leads to an interesting juxtaposition. Students felt somewhat less proficient with the learning outcome concerning the virtual CVD, as compared to the other learning outcomes (average scores of $72 \%$ versus 75.5\%). However, they felt that the virtual CVD was the most effective learning medium used in the course-even more so than physical laboratories ( $81 \%$ versus $75.5 \%)$. Although the students perceived the virtual CVD to be effective, after they completed the assignment, they only felt moderate mastery of the associated learning outcomes. These results highlight the complexity of the cognitive processes necessary to perform this task, which is precisely the benefit of applying instructional scaffolding.

\section{CONCLUSION}

A virtual CVD laboratory has been developed with the intent of complementing, not replacing, existing physical laboratories. The laboratory is designed to allow students to engage more fully in certain aspects of the experimental design process; specifically, the experimental strategy, the analysis and interpretation of data, and the iterative process of redesign. These aspects require higher level cognitive skills. The simulation of the CVD reactor is based on fundamental principles of mass transfer and chemical reaction, obscured by added "noise." The software application contains a 3-D student client that simulates a cleanroom environment, an instructor Web interface with integrated assessment tools, and a database server complete with calculation engine. The application has integrated assessment tools directly available enabling formative and summative assessment strategies.

The virtual CVD laboratory has been implemented at OSU and remotely at the UO. Assessment has been performed to measure ways in which the virtual CVD laboratory promotes student learning. Task analysis of "think-aloud" sessions verifies that students are engaged in the intended, iterative experimental design approach of practicing engineers. Additionally, personality dynamics of the team members played a significant role in the project direction. Student performance was shown to be proportional to the number of higher level cognition statements as classified by Bloom's taxonomy. As measured by end of course surveys, students felt somewhat less proficient with the learning outcome concerning the virtual CVD laboratory, as compared to the other learning outcomes. However, they felt that the virtual CVD was the most effective learning medium used in the course, even more so than physical laboratories.

\section{ACKNOWLEDGMENT}

The authors would like to thank Northwest Regional Educational Laboratory's E. Gummer, who consulted on the assessment design and implementation, and D. Meyers-Graham and J. Noffsinger, computer science undergraduates at OSU, for their contribution to the 3-D student client.

\section{REFERENCES}

[1] P. C. Wankat and F. S. Oreovicz, Teaching Engineering. New York: McGraw-Hill, 1993.
[2] J. Henry, "Running laboratory experiments via the world wide web," presented at the Annu. Amer. Soc. Engineering Education Conf. Exposition, Washington, DC, 1996.

[3] D. Gillet, H. A. Latchman, C. H. Salzmann, and O. D. Crisalle, "Hands-on laboratory experiments in flexible and distance learning," J. Eng. Educ., vol. 90, pp. 187-191, Apr. 2001.

[4] M. Ogot, G. Elliot, and N. Glumac, "An assessment of in-person and remotely operated laboratories," J. Eng. Educ., vol. 92, pp. 57-64, Jan. 2003.

[5] W. G. Hurley and C. K. Lee, "Development, implementation, and assessment of a web-based power electronics laboratory," IEEE Trans. Educ., vol. 48, no. 4, pp. 567-573, Nov. 2005.

[6] S. Sivakumar, W. Robertson, M. Artimy, and N. Aslam, "A web-based remote interactive laboratory for Internetworking education," IEEE Trans. Educ., vol. 48, no. 4, pp. 586-598, Nov. 2005.

[7] G.-W. Chang, Z.-M. Yeh, H.-M. Chang, and S.-Y. Pan, "Teaching photonics laboratory using remote-control web technologies," IEEE Trans. Educ., vol. 48, no. 4, pp. 642-651, Nov. 2005.

[8] A. Spanias and V. Atti, "Interactive online undergraduate laboratories using J-DSP," IEEE Trans. Educ., vol. 48, no. 4, pp. 735-749, Nov. 2005.

[9] P. J. Mosterman, M. A. M. Dorlandt, J. O. Campbell, C. Burow, R. Bouw, A. J. Brodersen, and J. Bourne, "Virtual engineering laboratories: Design and experiments," J. Eng. Educ., vol. 83, pp. 279-285, Jul. 1994.

[10] T. Wiesner and W. Lan, "Comparison of student learning in physical and simulated unit operations experiments," J. Eng. Educ., vol. 93, pp. 195-204, Jul. 2004.

[11] J. Richardson, N. Adamo-Villani, E. Carpenter, and G. Moore, "Designing and implementing a virtual 3D microcontroller laboratory environment," in Proc. 36th Annu. Frontiers in Education Conf., San Diego, CA, Oct. 2006, pp. 1-5.

[12] D. Rosenthal and D. Arnold, "Simulation of experimental data, the design of experiments, and the analysis of results: Kinetics of catalyzed ester hydrolysis," J. Chem. Educ., vol. 54, pp. 323-325, May 1977.

[13] R. Stolzberg, "Screening and sequential experimentation: Simulations and flame atomic absorption spectrometry experiments," J. Chem. Educ., vol. 74, pp. 216-220, Feb. 1997.

[14] B. Woodfield, M. Andrus, T. Andersen, J. Miller, B. Simmons, R. Stranger, G. Waddoups, M. Moore, R. Swan, R. Allen, and G. Bodily, "The virtual ChemLab project: A realistic and sophisticated simulation of organic synthesis and organic qualitative analysis," J. Chem. Educ., vol. 82, pp. 1728-1735, Nov. 2005.

[15] J. Campbell, J. Bourne, P. Mosterman, and A. Brodersen, "The effectiveness of learning simulations for electronic laboratories," J. Eng. Educ., vol. 91, pp. 81-87, Jan. 2002.

[16] E. D. Lindsay and M. C. Good, "Effects of laboratory access modes upon learning outcomes," IEEE Trans. Educ., vol. 48, no. 4, pp. 619-631, Nov. 2005.

[17] H. Hodge, H. S. Hinton, and M. Lightner, "Virtual circuit laboratory," J. Eng. Educ., vol. 90, pp. 507-511, Oct. 2001.

[18] J. M. Allwood, B. M. Cox, and S. S. Latif, "The structured development of simulation-based learning tools with an example for the Taguchi method," IEEE Trans. Educ., vol. 44, no. 4, pp. 347-353, Nov. 2001

[19] T. C. Harmon, G. A. Burks, J. J. Giron, W. Wong, G. K. W. K. Chung, and E. Baker, "An interactive database supporting virtual fieldwork in an environmental engineering design project," J. Eng. Educ., vol. 91, pp. 167-176, Apr. 2002.

[20] G. K. W. K. Chung, T. C. Harmon, and E. Baker, "The impact of a simulation-based learning design project on student learning," IEEE Trans. Educ., vol. 44, no. 4, pp. 390-398, Nov. 2001.

[21] S. Wolf and R. N. Tauber, Silicon Processing for the VLSI Era. Sunset Beach, CA: Lattice, 2000.

[22] A. J. Muscat, E. L. Allen, E. H. Green, and L. S. Vanasupa, "Interdisciplinary teaching and learning in a semiconductor processing course," J. Eng. Educ., vol. 87, pp. 414-421, Oct. 1998.

[23] J. P. Chang, "A hands-on laboratory in the fundamentals of semiconductor manufacturing: The capstone course of a new undergraduate option," Chem. Eng. Educ., Winter, 2002.

[24] C. Chang, M. D. Koretsky, S. Kimura, S. Rochefort, and C. Shaner, "Lab-based unit operations in microelectronics processing," Chem. Eng. Educ., pp. 188-195, Summer, 2003. 
[25] M. D. Koretsky, C. Barnes, D. Amatore, and S. Kimura, "Experiential learning of design of experiments using a virtual CVD reactor," presented at the Annu. Amer. Soc. Engineering Education Conf. Exposition, Chicago, IL, 2006.

[26] B. J. S. Barron, D. L. Schwartz, N. J. Vye, A. Moore, A. Petrosino, L. Zech, and J. D. Bransford, "Doing with understanding: Lessons from research on problem and project-based learning," J. Learn. Sci., vol. 7, pp. 271-311, Nov. 1998.

[27] D. R. Woods, Problem-Based Learning: How to Gain the Most From PBL. Waterdown, ON, Canada: McMaster Univ., 1994.

[28] R. H. Burning, Cognitive Psychology and Instruction. Upper Saddle River, NJ: Merrill, 1999.

[29] J. Bransford, A. Brown, and R. Cocking, How People Learn. Washington, DC: National Academies Press, 2000.

[30] B. S. Bloom, M. D. Engelhart, E. J. Furst, W. H. Hill, and D. R. Krathwohl, Taxonomy of Educational Objectives: The Classification of Educational Goals. New York: David McKay, 1956.

[31] J. S. Brown, A. Collins, and P. Duguid, "Situated cognition and the culture of learning," Educ. Res., vol. 18, no. 1, pp. 32-42, Jan.-Feb. 1989.

[32] [Online]. Available: http://cbee.oregonstate.edu/education/VirtualCVD, Nov. 21, 2006

[33] L. D. Feisel and A. J. Rosa, "The role of the laboratory in undergraduate engineering education," J. Eng. Educ., vol. 94, pp. 121-130, Jan. 2005.

[34] G. Wiggins and J. McTighe, Understanding by Design. Englewood Cliffs, NJ: Prentice-Hall, 2000.

[35] M. A. Ruiz-Primo, S. E. Schultz, M. Li, and R. J. Shavelson, "Comparison of the reliability and validity of scores from two concept-mapping techniques," J. Res. Sci. Teach., vol. 38, no. 2, pp. 260-278, Feb. 2001.

[36] J. W. Pelligrino, N. Chudowsky, and R. Glaser, Knowing What Student Know: The Science and Design of Educational Assessment. Washington, DC: National Academies Press, 2001.

[37] R. Shavelson, M. A. Ruiz-Primo, M. Li, and C. C. Ayala, Evaluating New Approaches to Assessing Learning, Univ. California, Los Angeles, 2003, Center for the Study of Evaluation Rep.
Milo D. Koretsky received the B.S. and M.S. degrees in chemical engineering from the University of California, San Diego, and the Ph.D. degree from the University of California, Berkeley, in 1984, 1985, and 1991, respectively.

He joined Oregon State University, Corvallis, in 1992. His current research activity includes areas related to thin film materials processing and engineering education. He authored Engineering and Chemical Thermodynamics, which includes an integrated, menu-driven computer program, ThermoSolver.

Dr. Koretsky has won awards for his work in engineering education at the university and national levels, and is a six-time Intel Faculty Fellow.

Danielle Amatore is working towards the Ph.D. degree in chemical engineering at Oregon State University, Corvallis.

Her research interests involve the simultaneous design of learning tools for engineering education while conducting research that contributes to learning theories.

Connelly Barnes is working towards the Ph.D. degree in computer science at Princeton University, Princeton, NJ.

He was an undergraduate student at Oregon State University, Corvallis, when he developed the architecture for the virtual CVD using Unix, Python, C++, and OpenGL.

Sho Kimura received the B.S. degree from Osaka University, Osaka, Japan, in 1967, the M.S. degree from Oregon State University (OSU), Corvallis, in 1976, and the Ph.D. degree from Osaka University in 1982, all in chemical engineering.

He is currently a Professor of Chemical Engineering at OSU. Prior to joining OSU in 1989, his work experience included 11 years in industry and 10 years in academia in Japan. He developed the mathematical model for the virtual CVD reactor. His research activities cover applications of fluidization technologies in high-temperature gas-solid reaction systems. 